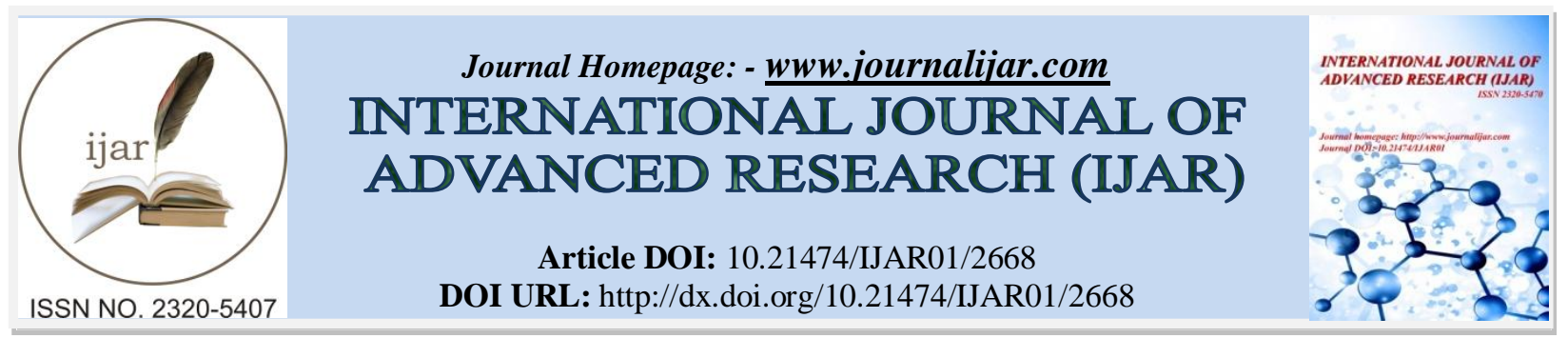

RESEARCH ARTICLE

\title{
MULTI-THERAPEUTIC ACTIVITY OF BERBERIS LYCIUM ROYLE: A REVIEW
}

\section{Manik Sharma ${ }^{1}$, Javaid Iqbal ${ }^{*}$, Som Kailash ${ }^{1}$, Mohd Asgher ${ }^{2}$, Mohd Younis ${ }^{3}$, Jagrati Tripathi ${ }^{4}$, Fakhar Shezad $^{5}$ and Meraj Ud Din Hura ${ }^{6}$.}

1. Department of Zoology, Bhoj Mahavidhyalaya Bhopal, Barkatullah University, Bhopal (M.P), India.

2. Center for Biodiversity, School for Biosciences and Biotechnology, BGSB University, Rajouri, J\&K, India.

3. Department of Human Genetics and Molecular Biology, Bharathiar University, Coimbatore, Tamil Nadu, India.

4. Department of Biotechnology, Unique College, Bhopal, Barkatullah University Bhopal (M.P), India.

5. Department of Botany, Govt. Beneezar College Bhopal, Barkatullah University, Bhopal (M.P), India.

6. Department of Zoology and Applied Aquaculture, Barkatullah University, Bhopal (M.P), India.

\section{Manuscript Info}

(..........................

Manuscript History

Received: 31 October 2016

Final Accepted: 30 November 2016

Published: December 2016

\section{Key words:-}

Berberis lycium, pharmacological value, antidiabetic, wound healing.

\section{Abstract}

Herbal medicine is getting popularized in developing and developed countries owing to its natural origin. Berberis lycium (Berberidaceae) is an evergreen shrub 2-3 m in height. It is also known as Indian Barberry in English, Kashmal in Hindi and Ishkeen in Urdu. Its local name is Simbulu in District Rajouri in Jammu and Kashmir (J\&K), India. Traditionally, Berberis lycium is used by the Tribal peoples in $\mathrm{J} \& \mathrm{~K}$, India, since the time immemorial. The phytochemical investigation showed the presence of alkaloids, tannins, terpenoids, phenols, flavonoids, fats and proteins. Its roots are yellow in colour, rich in alkaloids Berberine etc. Pharmacological investigation has shown that it exhibits antibacterial, antidiabetic, hepatoprotective, pesticidal, antimutagenic, wound healing, anticancer, antimicrobial, antihyperlipidemic and antifungal properties, supporting its traditional uses. Moreover, it has also edible properties. The present review article overview the ethnomedicinal, chemical, nutritional constituents and pharmacological properties of the plant and in this article attempt has been made to summarize the different properties of the plant.

Copy Right, IJAR, 2016,. All rights reserved.

\section{Introduction:-}

Medicinal plants are those which have some medicinal properties. According to the World health Organization (WHO, 1977) "A medicinal plant" is any plant, in which one or more of its organ contains substances that can be used for the therapeutic purposes or which are precursors for the synthesis of useful drugs. Medicinal plants are very useful as they are easily available source for health purposes in rural and tribal areas. Plant kingdoms are the rich source of organic compounds, many of which have been used for medicinal purposes. In traditional medicine, there are many natural crude drugs that have the potential to treat many disease and disorders. One of them is Berberis lycium (Berberidaceae), a lesser- known plant is named in English as barberry (Anwar et al., 1979), whereas, its fruit is called as "Kashmal" (Baquar, 1989; Usmanghani et al., 1997) and roots are known as "Darhald" (Nadkarni, 1980). The family Berberidaceae was first established by Jussieu A. L. de 1789 (Hasnain 2014) as 'Berberides' and

Corresponding Author:- Javaid Iqbal.

Address:- Department of Zoology, Bhoj Mahavidhyalaya Bhopal, Barkatullah University, Bhopal, (M.P), India. 
was considered one of the most primitive angiosperms having a high number of discontinuous genera (Bruckner, 2000). Berberidaceae is a heterogeneous assemblage of angiosperms comprising 17 genera and 650 species in the world, which are distributed mostly in the northern hemisphere. Berberis lycium is found through the temperate and subtropical regions of the world (apart from Australia). Berberis lycium is native to Nepal, globally distributed in various part of the world. It occurs in subtropical and temperate regions from Kashmir to Uttaranchal on the outer Northern-western Himalayas (Sharma, 2003). Berberis lycium is locally known as Simbulu by the peoples of Rajouri and Poonch in Jammu and Kashmir, India. It is mostly used by the tribal peoples in twin border district Rajouri and Poonch in J\&K, India, for the treatment of many diseases e.g. wound healing, jaundice, cough and throat pain, etc. since the time immemorial. The plant is rich in nutritional elements. Traditionally the plant has been used against diarrhea (Zaman and Khan, 1970), Intestinal colic (Kaur et al., 2001), Diabetes (Ahmed et al., 2004), throat pain, scabies, bone fractures, sun blindness and fever (Ahmed et al., 2004 and Kaur et al., 2001). Internal wounds (Hamayun et al., 2005).

Plant extracts are the most widely used natural medicine due to their ease of availability and comparatively low production cost. The use of plant products as medicine in treatment of various chronic diseases or disorder is supported by Ayurveda, a system of traditional medicine native to the Indian sub-continent and also practised in other part of the world as a form of alternative medicine (Patwardhan and Hopper, 1992).

Berberine is a plant alkaloid with a long traditional history that is used both in Ayurvedic and Chinese medicine. Berberine is chief alkaloid from roots and stem bark of Berberis species. It is manufactured mostly from roots of Berberis aristata (5\% in roots and $4.2 \%$ in stem bark), B. Petiolaris $(0.43 \%)$, B. Vulgaris, B. Aquifolium, B. Thunbergii and B. Asiatica (Watt, 1972; Nandkarni, 1976; Chopra, et al., 1996), C. Teeta (rhizome 8-9\%) and Hydrastis Canadensis (Gruenwald, et al., 2000).

As a drug, it is traditionally used for its antimicrobial and antiprotozoal properties in Ayurveda, Chinese and Middle-Eastern folk medicine (Arayne et al., 2007) Berberine has various other pharmacological properties and medicinal uses that are beneficial in the treatment of chronic ailments or diseases including diabetes, cancer, depression, hypertension and hypercholesterolemia etc. ( Imanshahidi and Hosseinzadeh, 2008).

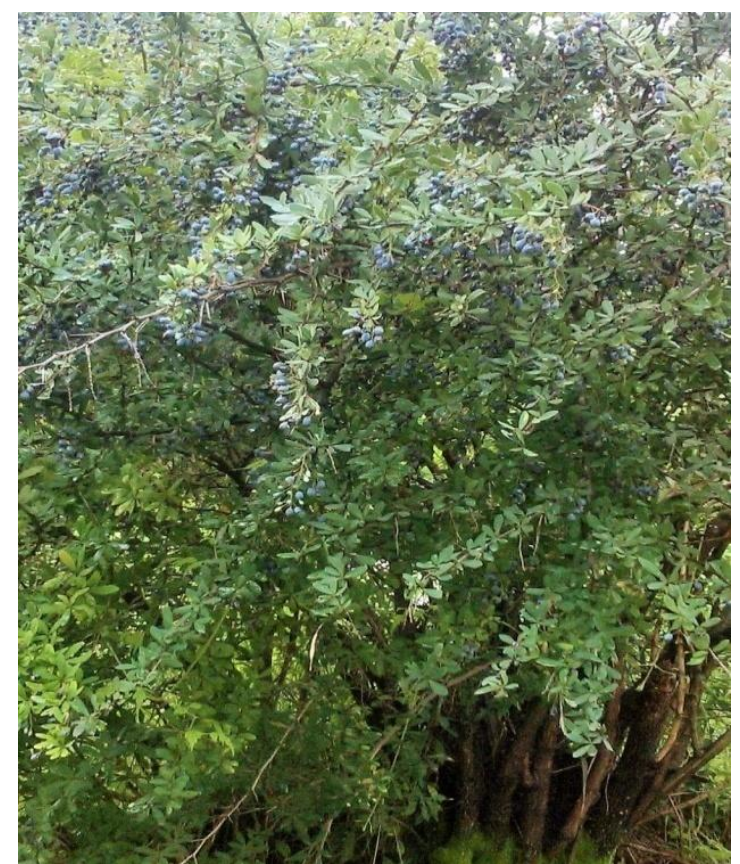

Figure: Depicting Berberis lycium Royle in fruit stage

\section{Phytochemical and Nutritional Constituents:-}

Berberis lycium is rich in nutritional value. Various parts of the plant were traditionally used to cure different diseases and for healing wounds. Berberis lycium contains alkaloids like Berberine (Ali and Khan, 1978; Chandra and Purohit, 1980; Gulfraz et al., 2004) palmitine (Gosh et al., 1990; Gulfraz et al., 2004), berbamine, 
baluchistanamine, karakoramine, gilgitine, jhelumine, punjabine, sindamine, chinabine (Manske, 1998) and umbellatine (Baquar, 1989). A wide variety of minerals are also documented such as sodium, calcium, sulphur, iron, zinc, (Gulfraz et al., 2004), copper, lead and manganese (Srivastava et al., 2006). The plant is also documented to possess hydrolysable tannins, cardioactive glycoside and saponins (Ahmed et al., 2009a). It was revealed that Zinc, $\mathrm{Cu}$ and Sodium were maximum in roots while $\mathrm{Mn}$, Phosphorous and Calcium in leaves, whereas Potassium in shoot (Shah et al., 2003). Three new alkaloids are also found in the roots of Berberis lycium -baberine, melting point (M.P) $152^{\circ} \mathrm{C}\left(\mathrm{C}_{19} \mathrm{H}_{21} \mathrm{NO}_{3}\right)$, berbericine hydrochloride, M.P. $199{ }^{\circ} \mathrm{C}\left(\mathrm{C}_{20} \mathrm{H}_{17} \mathrm{NO}_{4} \mathrm{Cl}\right)$ and berbericine hydroiodide, M.P. $205{ }^{\circ} \mathrm{C}\left(\mathrm{C}_{21} \mathrm{H}_{22} \mathrm{NO}_{4} \mathrm{I}\right)$. Two artefact alkaloids berberine-chloroform, palmitine-chloroform along with oxyberberine, Umbellatine, berberine and berbamine was also identified in the roots of same species. In addition, three new seco-bisbenzylisoquinolines sindamine (monophenolic base) $\mathrm{C}_{37} \mathrm{H}_{38} \mathrm{O}_{8} \mathrm{~N}_{2}$; Punjabine (Secodimer Monophenolic base) $\mathrm{C}_{35} \mathrm{H}_{32} \mathrm{O}_{7} \mathrm{~N}_{2}$; Gilgitine (Secodimer monophenolic base) $\mathrm{C}_{36} \mathrm{H}_{34} \mathrm{O}_{8} \mathrm{~N}_{2}$. Punjabine and gilgitine are the first secodimeric alkaloids derived from in vivo oxidation of bis benzylisoquinoline precursor in corporating three diaryl ether bridges. Kara-koramine $\mathrm{C}_{25} \mathrm{H}_{27} \mathrm{O}_{5} \mathrm{~N}$, monophenolic chenabine $\mathrm{C}_{37} \mathrm{H}_{40} \mathrm{O}_{7} \mathrm{~N}_{2}$ and diphenolic jhelumine $\mathrm{C}_{36} \mathrm{H}_{38} \mathrm{O}_{7} \mathrm{~N}_{2}$ (more polar than chenabine) (Miana, 1973; Datta et al., 1976; Leet et al., 1982; 1983; Ikram et al., 1996).

Some isolated compounds and their Structures from the plant Berberis lycium Royle are as given below:<smiles>COc1cc2c(cc1OC)-c1cc(OC)c(OC)cc1-c1cc3ccc(OC)c(OC)c3c[n+]1CC2</smiles><smiles>CCN(C)Cc1cc2c(OC)cc1CCN(C)CC1Cc3ccc(O)c(c3)Oc3ccc(cc3)CCc3cc(OC)c(c(OC)c31)O2</smiles> 


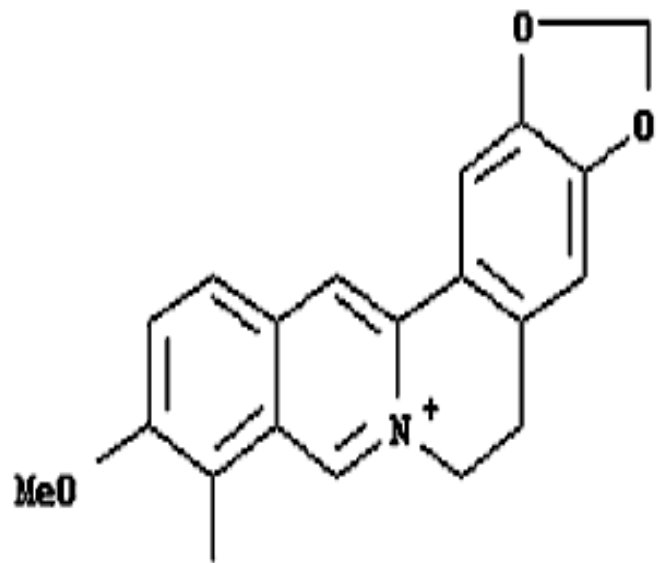

OXe

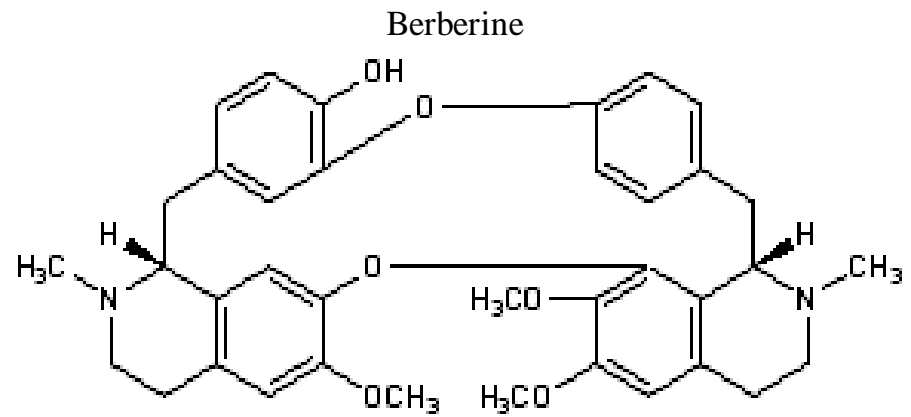

Oxyacanthine

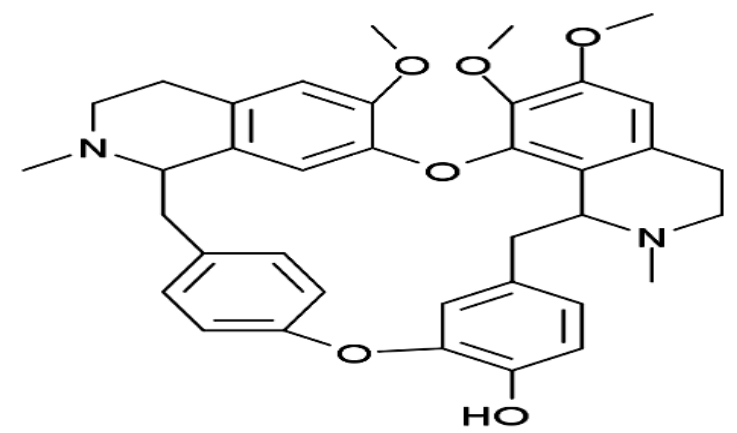

Berbamine

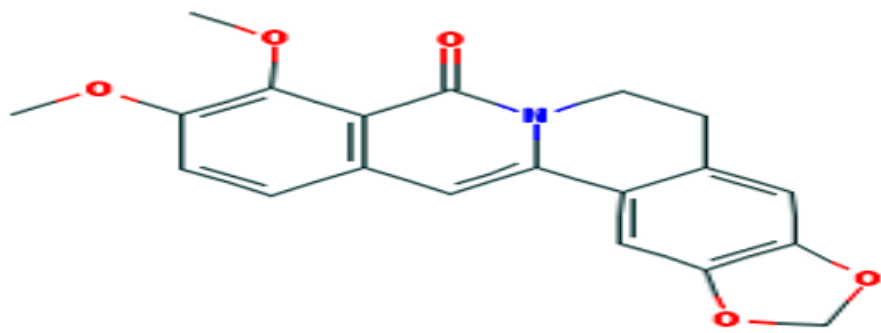

Oxyberberine 


\section{Pharmacological uses of Berberis lycium Royle:- Antidiabetic activity:-}

Many species of Berberies have been found to have antidiabetic property. Berberis lycium various root extracts lower the glucose level significantly (Hasnain, 2014). Crude powder of B. lycium reduced the blood glucose levels of both diabetic and normal rabbits. Water, methanolic, aqueous methanolic, $n$-hexane and chloroform extracts of plant were prepared for screening their antidiabetic activity in alloxanized rabbits. Results indicated that among the extracts, orally administered $500 \mathrm{mg} / \mathrm{kg}$ of water extract produced maximum hypoglycemic activity for up to $6 \mathrm{~h}$. Same doses of methanolic, aqueous methanolic and n-hexane extracts decreased blood glucose level up to $4 \mathrm{~h}$. Water extract was further compared in combination with insulin. The results of $500 \mathrm{mg} / \mathrm{kg}$ of water extract with 2 units of insulin were comparable with 6 units of insulin (Ahmad et al., 2009b). Ethanolic and aqueous extracts of plant roots were administered in normal and alloxanized rats and $20 \mathrm{mg} / \mathrm{kg}$ Glibenclamide was used as reference drug. Serum was utilized to evaluate blood glucose level by the glucose oxidase method. The doses of 50 and 100 $\mathrm{mg} / \mathrm{kg}$ decreased hyperglycemia after 3 to $5 \mathrm{~h}$ of treatment but the effect of later dose was more pronounced. Oral glucose tolerance test showed that plant extracts reduced serum glucose level in a dose-dependent manner. The observed mechanism involved in hypoglycemia is insulin- like effect, possibly through Berberine reduced blood glucose level significantly and demonstrated significant effects on glycosylated haemoglobin, glucose tolerance, serum lipid profiles and body weight. Plant extract was comparable in efficacy with Berberine (Gulfraz et al., 2007). Oral administration of $50 \mathrm{mg} / \mathrm{kg}$ of Berberis extract and berberine to normal and experimental diabetic rats produced a significant $(\mathrm{p}<0.05)$ reduction in blood glucose levels from 3-7 days of treatment. Significant effects were also observed on the glucose tolerance, glycosylated haemoglobin, serum lipid profiles and body weight of experimental animals. Berberis extract and berberine demonstrated similar effects on all parameters measured and although the extract was comparable in efficacy to berberine, it did not produce any effects additional to those shown by pure berberine (Gulfraz et al., 2008).

Berberine has shown marked impact on carbohydrate and lipid metabolism. It has a strong impact on glucose homeostasis. In fact, berberine increase insulin receptor mRNA through kinase C-dependent protein as promoter in cultured human liver cells and skeletal muscle (Kong et al., 2009). Berberine has been shown to provide protection against $\beta$-cell damage and protection of pancreas from oxidative stress in diabetic rats. Diabetic and hyperlipidemic condition was induced in rats by intraperitoneal injection of $35 \mathrm{mg} / \mathrm{kg}$ Streptozotocin and administration of highcarbohydrate/high-fat diet. The experiment was conducted by using seven groups of rats consisting of diabetic untreated and treated rats with 75/150/300 mg/kg berberine, rosiglitazone $4 \mathrm{mg} / \mathrm{kg}$ and fenofibrate $100 \mathrm{mg} / \mathrm{kg}$, and a control group. After 16 days of treatment, it was observed that the diabetic rats showed alteration in pancreas to body weight ratio, insulin level, insulin sensitivity index, malonaldehyde content and superoxide dismutase activity. The rats treated with 150 and $300 \mathrm{mg} / \mathrm{kg}$ berberine showed near control levels in evaluating the parameters. The pancreatic islets were found to be atrophied and the numbers of secretary granules were decreased in diabetic rats. This finding suggests that berberine has a protective effect for diabetes through increasing insulin expression, $\beta$-cell regeneration, antioxidant enzyme activity and decreasing lipid peroxidation (Zhou et al., 2009a).

Berberine has been shown to regulate glucose and lipid metabolism in vitro and in vivo. In study A, 36 adults with newly diagnosed type 2 diabetes mellitus were randomly assigned to treatment with berberine or metformin $(0.5 \mathrm{~g}, 3$ times a day) in a 3-month trial. The hypoglycemic effect of berberine was similar to that of metformin. Significant decrease in haemoglobin A (lc) was observed (Yin, et al., 2008).

\section{Antimicrobial property:-}

The roots are the most important part of Berberies species as they contain a number of alkaloids, the most prominent one is Berberine. It was found that inhibitory activity was shown by the components present in the root extract of Berberis lycium and not by the solvents used for extraction (Irshad et al., 2013). Hydroalcoholic (50\%) extract of air dried root and stem of B. lycium were used to determine antibacterial activity against Micrococcus luteum, Bacillus subtilis, Bacillus cereus, Enterobactor aerogenus, Escherichia coli, Klebsiella pneumonia, Proteus mirabilis, Pseudomonas aeruginosa, Staphylococcus aureus, Salmonella typhimurium and Streptococcus pneumonia. Root extract was also found active against Aspergillus spinulosus and Aspergillus flavus at MIC 0.62 and $1.25 \mu \mathrm{g} / \mathrm{ml}$, respectively (Singh et al., 2007). The hydroalcoholic extract exhibited stronger and broader spectrum against bacterial strains as compared to fungal strains (Singh et al., 2009). B. lycium showed better immune performance against new castle disease, infectious bursal disease and infectious bronchitis. A significant reduction in coccidial oocysts per gram of faeces was also noticed (Nidaullah et al., 2010). 
Berberine usually available as chloride and sulphate salts has a high bacteriostatic activity against Staphylococcus epidermis, Neisseria meningitides and E. coli. Berberine is specifically effective against Cholera, Giardia, Shigella and Salmonella (Chevalier, 2001). The antimicrobial activity of berberine, has evaluated the microbial effect of the drug against 17 Gram-positive and - negative microorganisms on the basis of $\mathrm{IC}_{50}$, MIC, minimum microbicidal concentration (MMC) and minimum microbistatic concentration (MMS). The $\mathrm{IC}_{50}$ value obtained for $\mathrm{S}$. Aureus was $14.6 \mathrm{mg} / \mathrm{ml}$, while for Bacillus subtilis was $43 \mathrm{mg} / \mathrm{ml}$. The high value in the latter case could be attributed to the development of resistance by the spores. It shows that berberine has marginal action on both Gram-positive and negative organisms (Cernakova and Kostalova, 2002). The National Institute of Health has also reported that extracts of berberine have demonstrated significant antimicrobial activity against bacteria, fungi, viruses and Chlamydia, confirming the antimicrobial activity of the drug (Sack and Froehlich, 2000). Berberine could inhibit Aspergillus fumigates through the ergo sterol biosynthesis pathway (Gao et al., 2011a). In macrophages, berberine chloride-mediated anti-leishmanial activity was through activating p38 MAPK along with inhibiting ERK1/2 (Saha et al., 2011). Berberine chloride could also induce Leishmania donovani promastigote apoptosis-like deaths accompany with increased generation of reactive oxygen species (Saha et al., 2009).

\section{Wound healing property:-}

Aqueous and methanol Root extracts of B. lycium of the plant were studied for wound healing activity using, excision, incision and dead wound space models of wound repair. Both extracts increased the area of epithelialization and also showed increase in breaking strength. In aqueous extract treated group moderate collagen deposition, macrophages and fibroblasts were found, whereas a significant rise in collagen deposition with lesser macrophages and fibroblasts were observed in methanol extract treated group. It was revealed that methanolic extract was more efficient than the aqueous extract (Asif et al., 2007).

\section{Antimutagenic property:-}

Root extracts of B. lycium were for evaluated for Anti-neoplastic activities using p53 deficient HL-60 cells along with Berberine and palmatine. The n-butanol extract demonstrated highest toxicity against HL-60 cells (IC50 $2.3 \mu \mathrm{g}$ extract / $\mathrm{ml}$ medium after $48 \mathrm{~h}$ of treatment), followed by the ethanol extract $(23.5 \mu \mathrm{g} / \mathrm{ml})$ and the water extract $(110$ $\mu \mathrm{g} / \mathrm{ml})$. Berberine showed IC50 $1.2 \mu \mathrm{g} / \mathrm{ml}$ after $48 \mathrm{~h}$ of treatment, while palmatine did not exhibit inhibitory effect on cell growth. HL-60 cells were exposed to $5.5 \mu \mathrm{g}$ butanol extract $/ \mathrm{ml}$ and $0.6 \mu \mathrm{g}$ Berberine $/ \mathrm{ml}$ for $48 \mathrm{~h}$ to evaluate the cell cycle distribution which resulted in reduction of G1 cells and accumulation of cells in the S-phase by both plant extract and Berberine. Both induced apoptosis in HL-60 cells without concomitant induction of $\gamma \mathrm{H} 2 \mathrm{AX}$, which shows that the anti-neoplastic effects have not been stimulated by Berberine-caused genotoxicity. Chk2 also became activated and pattern was found correlated with the accumulation of cells in S- phase. Cdc25A proto-oncogene inactivation was the earliest event exhibited by the Berberine and butanol extract, followed by the acetylation of $\alpha$ tubulin, activation of Chk2 and p38, and the down-regulation of cyclin (Khan et al., 2010).

\section{Hepatoprotective property:-}

To evaluate hepatoprotective effect, crude powder and methanolic extract of B. lycium was used. Paracetamol was used to induce hepatotoxicity in rabbits. Results showed that plant significantly reduced the raised levels of alkaline phosphatase, serum glutamic pyruvic transaminase and serum glutamic oxaloacetic transaminase enzymes in treated hepatotoxic rabbits (Ahmad et al., 2008). In another study, six poly herbal formulations including Livokin (Herbomed, Kolkata) which also contains B. lycium were studied in mice. This formulation was found to have hepatoprotective effect in paracetamol induced hepatotoxic mice (Girish et al., 2009). Powder of B. lycium bark along with Pistacia integerrima and Gallium aparine were mixed in distilled water (2,1 and $1 \mathrm{mg} / \mathrm{ml}$, respectively) and shaken vigorously. Carbon tetrachloride was used to induce hepatotoxicity in male Sprague-Dawley rats. Study indicated that these medicinal plants have more effect as curative agents rather than preventive agents (Khan et al., 2008).

Berberine $120 \mathrm{mg} / \mathrm{kg}$ b.w. and Coptidis rhizomes aqueous extract at doses of 400,600 , and $800 \mathrm{mg} / \mathrm{kg} \mathrm{b}$. W. Were orally givens to rats after $6 \mathrm{hr}$ of $\mathrm{CCl} 4$ treatment. The results showed that Coptidis rhizome aqueous extract and berberine inhibited significantly the activities of alanine aminotransferase and aspartate aminotransferase and increases the activity of superoxide dismutase. Coptidis rhizome aqueous extract has hepatoprotective effect on acute liver injuries induced by $\mathrm{CCl} 4$, and the results suggested that the effect of Coptidis rhizome aqueous against CCl4-induced liver damage is related to antioxidant property (Xingshing, et al., 2009).berberine could inhibit liver fibrosis. In liver fibrosis rodent models, it could protect experimental liver fibrosis through enhancing anti-oxidant system, inhibiting lipid peroxidation and hepatic satellite cell proliferation (Sun et al., 2009a; Zhang et al., 2008a). 


\section{Antihyperlipidemic property:-}

Antihyperlipidemic property was investigated and roots of $B$. lycium were collected for this purpose. Results indicated that oral administration of 250 and $500 \mathrm{mg} / \mathrm{kg}$ crude powder for 4 weeks resulted in significant decline in triglyceride, low density lipids (LDLs) and total cholesterol levels in male albino rabbits, while high density lipids (HDLs) were enhanced. Furthermore, same doses stabilized the weight of diabetic rabbits (Ahmad et al., 2009b). In another study, B. lycium root bark powder was studied for hypolipidemic effect in broilers. The powder was added to commercial broiler feed at the rate of $2.0 \%$. B. lycium crude powder significantly decreased the total cholesterol, triglycerides and LDL, while HDL was significantly increased dose dependently (Chand et al., 2007).

Berberine have been widely investigated in lipid metabolism, it has been observed that berberine was capable of lowering lipid concentration by increasing the transcriptional activity of LDLR promoter by a JNK pathway and stabilization of hepatic LDL-C receptor (LDLR) by an extracellular signal-regulated kinase (ERK)-dependent pathway (Abidi et al., 2005; Lee et al., 2007).

\section{Pesticidal property:-}

Petroleum ether and aqueous methanol extracts of B. lycium root was prepared using Soxhlet apparatus and dried under vacuum. The activity of plant extracts were tested at two higher doses (5000 and $10000 \mathrm{ppm}$ ) against pests. Petroleum ether extract showed 25\% mortality rate against Helicoverpa armigera Hub and $92 \%$ mortality rate against Aphis craccivora Koch at the dose of $5000 \mathrm{ppm}$. Extract also exhibited 26\% mortality rate against Tetranychus urticae Koch, $98 \%$ mortality rate against $A$. craccivora Koch, while $28 \%$ mortality rate against $H$. armigera Hub and Plutella xylostella L. each at the dose of 10,000 ppm. Petroleum ether extract inhibited $A$. craccivora Koch at 458.65 ppm lethal concentration at 50\% (LC50) after $24 \mathrm{~h}$ contact time and 57.79 ppm LC50 after $48 \mathrm{~h}$ contact time. The LC50 at $48 \mathrm{~h}$ exposure was nearly comparable with that of Dimethoate (a chemical insecticide) at $24 \mathrm{~h}$ exposure. Aqueous methanolic extract demonstrated $26 \%$ mortality rate against $\mathrm{A}$. craccivora Koch at the dose of $5000 \mathrm{ppm}$. Extract also showed $44 \%$ mortality rate against $H$. armigera Hub, $41 \%$ against $P$. xylostella L., $43 \%$ against $T$. urticae Koch and 68\% against $A$. craccivora Koch (Tewary et al., 2005).

\section{Anticancer activity:-}

The cytotoxic effect of berberine in cell lines was assessed by using trypan blue exclusion assay. Surprisingly, berberine at 5-200 $\mu \mathrm{M}$ concentration was found to induce cell death in a dose-dependent manner. Treatment of cells with a $200-\mu \mathrm{M}$ concentration of berberine for $5 \mathrm{~h}$ yielded a $\mathrm{LD}_{50}$. The extent of DNA damage and repair after berberine treatment $(0-100 \mu \mathrm{M})$ was also evaluated, using comet assay. Administration of berberine up to $20 \mu \mathrm{M}$ caused irreparable cell damage, as indicated by the increase in tail DNA content. However the repair of DNA damage on this cell line in presence of $\mathrm{H}_{2} \mathrm{O}_{2}$ occurred within $1.5 \mathrm{~h}$, indicating that berberine has contributed in the process of DNA repair inhibition which finally resulted in the cell death (Szeto et al., 2002).

Berberine could induce cell death in diverse cancer cells, such as breast cancer, liver cancer and lung cancer. Apoptosis was the most common way involved in berberine-induced cancer cell death in many cell lines and cancer cell xenograft (Choi et al., 2009). On the other hand, autophagy and necrosis were also reported to be associated with berberine-induced cancer cell death (Letasiova et al., 2006; Hou et al., 2011).

\section{Antidepressant activity:-}

Neuropsychiatric research investigated the CNS effects of berberine. It demonstrated that berberine also possesses an antidepressant activity (Kulkarni and Dhir, 2007). It was found that the drug affected the signalling pathway of Larginine-NO cGMP, which manifested the antidepressant activity of the drug. The antidepressant activity was confirmed by conducting forced-swim test (FST) and tail-suspension test (TST) (Kulkarni and Dhir, 2008). Total immobility period was recorded during a 6 - min test. Berberine $(5-20 \mathrm{mg} / \mathrm{kg}$, i. p.) produced a reduction in immobility period in both tests. When berberine $(5 \mathrm{mg} / \mathrm{kg}$, i. p.) was co-administered with other typical antidepressant drugs such as mianserin $(32 \mathrm{mg} / \mathrm{kg}$, i. p.) or trazodone $(2 \mathrm{mg} / \mathrm{kg}$, i. p.) it was found to improve the anti-immobility effect of sub effective doses of the two antidepressant in FST but did not modify their effects. Berberine $(5 \mathrm{mg} / \mathrm{kg}$, i. p.) increased the levels of nor epinephrine, serotonin or dopamine in the mouse whole brain.

Berberine is also known to bind sigma like many synthetic antidepressant drugs. As berberine is a natural compound that has been safely administered to humans, preliminary results suggests the initiation of clinical trials in patients with depression, bipolar affective disorder, schizophrenia or related diseases in which cognitive capabilities are affected with either the extract or pure berberine (Kulkarni and Dhir, 2009). 


\section{Antihypertensive activity:-}

Berberine acts on both endothelium and underlying vascular smooth muscle to induce vasorelaxation via multiple cellular mechanisms. It has been proposed that at lower concentrations berberine-mediated aortic relaxation appears to be dependent on its effects on endothelium, while at higher concentrations the effects induced by the drug are independent of the presence of intact endothelium (Wong, et al., 1998). Other mechanism involved have also been suggested that include ACE-inhibitor effect, direct release of NO/cGMP from rat aortic rings, increased sensitivity to the acetylcholine action, and activation of $\mathrm{K}^{+}$channels (Chiou, et al., 1991; Olmez and Ilhan, 1992; Kang, et al., 2002 ) Berberine was found to decrease the frequency and complexity ventricular premature complexes and increase the left ventricular ejection fraction in chronic heart failure patients. In patients with ventricular tachyarrhythmia, berberine produced $\geq 50 \%$ reduction in ventricular premature contraction in $62 \%$ and $\geq 90 \%$ reduction in $38 \%$ of patients (Lau, et al., 2001).The alkaloids produces long lasting, dose related fall in blood pressure of anaesthetized rabbits (Watt, 1972). Fractions from the root extracts of B. Vulgaris, which contain $80 \%$ berberine and other alkaloids, have been shown to reduce the blood pressure of cats for several hours. With varying doses, both positive and negative ionotropic effects on the Cats hearts were recorded (Lahiri, et al., 1958). Infusion of berberine when given intravenous to rats reduces blood pressure (Anonymous, 1976).

\section{Anti-inflammatory activity:-}

Berberine showed positive anti-inflammatory effects in vivo and in vitro study in Wister rats. A $12 \mathrm{hr}$ berberine treatment at concentrations of 1,10 , and $100 \mathrm{mM}$ in oral cancer cell line OC2 and KB cells showed reduced prostaglandin E2 (PGE2) production dose-dependently with or without 12-O-tetradecanoylphorbol-13-acetate (TPA) $(10 \mathrm{nM})$ induction. Berberine effect occurred rapidly after $3 \mathrm{hr}$ as a result of reduced COX-2 protein but not enzyme activity. Berberine exhibits its anti-inflammatory effect through reduced COX-2 protein but not enough inhibition of enzyme activity (Kou et al., 2004).

\section{Hypolipidemic activity:-}

Berberine activates AMP-activated protein kinase (Turner, et al., 2008) specifically extracellular signal-regulated kinase (Lamontagne, et al., 2009), which plays a central role in glucose and lipoid metabolism (Lee, et al., 2006)suppresses pro-inflammatory cystokines (Jeong, et al., 2009), and reduces MMP-9 and EMMPRIN expression (Huang, et al., 2009), which are all beneficial changes for heart health. Berberine also prevents proliferation of hepatic stellate cells, which are central for the development of fibrosis during liver injury (Sun, et al., 2009b). Moreover, berberine reduces hepatic fat content in the rats of non-alcoholic fatty liver disease.

In small clinical trials, berberine play an important role in the treatment of type 2 diabetes via lowering blood free fatty acids, such as triglyceride, total cholesterol and LDL-C (Zhang et al., 2008c; Gu, et al., 2010).

\section{Protective effect of Islets:-}

Berberine was able to protect islet cells from injure. In HIT-T15 pancreatic $\beta$-cells, it can reduce palmitate-induced beta-cell lipoapoptosis probably via up regulating PPAR $\gamma$ expression (Gao, et al., 2011b). In nonobase diabetic mice, berberine supplementation could significantly increase the number of decreased islets and ameliorate insulin and blood lipid status (Chueh and Lin, 2011). In type 1diabetic mice, it could inhibit T cell-mediated destruction of islet beta cells and severe islet inflammation through suppressing Th17 and Th 1 differentiation (Cui et al., 2009a). In diabetic rats, it could also increase islet beta cell regeneration, antioxidant enzyme activity and decrease lipid peroxidation, therefore protect islets from oxidative damage (Zhou et al., 2009b).

\section{Ant diarrheal activity:-}

Berberine directly inhibits some Vibrio cholera and E. coli enterotoxins significantly, reduce smooth muscle contraction, intestinal motility and delays intestinal transit time in humans (Sack and Frochlich, 1982; Yuan et al., 1994). In vitro study indicates that berberine sulphate inhibits bacterial adherences to mucosal or epithelial surfaces, which is the first step in the infective process. This may be a result of berberine's inhibitory effect on fimbrial structure formation on the surface of the bacteria (Sun, et al., 1988). In mice, berberine has shown some activity against $E$. histolytica, this make it useful against bilious disorder (Hostettmann, et al., 1995).

\section{Trachoma:-}

Berberine has more effective than sulfacetamide in eradicating Chlamydia trachomatis from the eye and preventing relapse of symptoms (Babbar, 1982; Mohan, 1982). 


\section{Anti-arrhythmic activity:-}

Berberine and its derivatives, tetrahydroberberine and 8-oxoberberine effects are attributed to the blockade of $\mathrm{K}+$ channels (delayed rectifier and $\mathrm{K}(\mathrm{ATP})$ ) and stimulation of $\mathrm{Na}+-\mathrm{Ca}(2+)$ exchanger. Berberine has been shown to prolong the duration of ventricular action potential. Its vasodilator activity has been attributed to multiple cellular mechanisms. The cardiovascular effect of berberine suggests its possible clinical usefulness in the treatment of arrhythmias and/or heart failure (Lau, et al., 2001).

\section{Genitourinary system:-}

The beneficial effect of berberine on renal functional and its possible mechanisms in rats with diabetic nephropathy, showed that oral administration of berberine $(200 \mathrm{mg} / \mathrm{kg} \mathrm{b}$.w.) significantly ameliorated the ratio of kidney weight to body weight. Glomerular area, glomerular volume, fasting blood glucose, blood urea nitrogen, serum Creatinine and urine protein for $24 \mathrm{hrs}$ were significantly decrease in the berberine treatment group, compared with the diabetic model group $(\mathrm{p}<0.05)$. Berberine treatment significantly increased serum SOD activity and decreased the content of MDA compared with diabetic model group $(\mathrm{p}<0.05)$. Aldose reductase activity as well as the expression of Aldose reductase mRNA and protein in the kidney was markedly decrease in the berberine treatment group compared with the diabetic model group ( $<<0.05)$ (Liu, et al., 2008).

\section{Antiprotozoal activity:-}

The crude extracts of berberine have shown to be more effective than its salts (Kaneda et al., 1990). The drug has the ability to suppress organism maturation through inhibition of its multiplication, respiration and macromolecular biosynthesis of amastigote forms of the parasite and interference with nuclear DNA of the promastigote form (Ghosh et al., 1985). In a clinical trial, berberine administration improved gastrointestinal symptoms and resulted in a marked reduction Giardia positive stools and it was effective at half the dose of the popular Giardiasis medication, metronidazole (Choudhary et al., 1972).

Berberine has been shown to give rise to a statistically significant prolongation of the lives of rats infected with Trypanosoma equiperdum (Serry and Bieter, 1940). Berberine sulphate has been shown to inhibit the growth of Entamoeba histolytica, Giardia lamblia and Trichomonas vaginalis, in vitro. The parasites all exhibited morphological changes after exposure to berberine sulphate (Kaneda, 1991).

\section{Antifungal activity:-}

Berberine hydrochloride was tested for their effects on Candida species, the colour stability of the dental material and the surface roughness of acrylic resin plates. The results of these tests revealed that the trial denture cleanser removed $64 \%$ to $89 \%$ of adhered cells from acrylic resin surfaces and had little effect on the physical properties tested (Nakamoto, et al., 1995). The extract of Berberis vulgaris with $80 \%$ berberine and additional alkaloids stimulated the bile excretion of rats by $72 \%$. Berberine has been shown to lower bilirubin levels (Chan, 1977).

\section{Antiplatelet activity:-}

Berberine significantly inhibited synthesis of thromboxane $\mathrm{A}_{2}$ in rabbit platelets induced by adenosine diphosphate, arachidonic acid or collagen in which collagen-induced thromboxane A2 synthesis was also most potentially inhibited. The plasma prostacyclin level was reduced by $34.6 \%$ during a 30 -min period after intravenous administration of $50 \mathrm{mg} / \mathrm{kg}$ of berberine (Huang, et al., 2002).

\section{Antibacterial activity:-}

Berberine was found to be the active constituent in an extract of Hydrastis canadensis root that demonstrated activity against a multiple drug-resistant strain of Mycobacterium tuberculosis (Gentry, 1998). Berberine is reported to inhibit Helicobacter pylori (Bae, 1998). Berberine is also active against other intestinal infections that cause acute diarrhea such as Shigella dysenteriae, Salmonella paratyphi and various Klebsiella species. Berberine sulphate has been shown to block the adherence of Streptococcus pyrogenes and E. coli to host cells, possibly explaining its mechanism of action against numerous pathogens (Sun, et al., 1988).

\section{Conclusion:-}

Berberis lycium is native to the whole region of Himalayas Mountains and is widely distributed in temperate and semi temperate areas of India, Pakistan, Afghanistan, Nepal and Bangladesh. It has various pharmacological actions some of them are reported above. Berberis lycium is a widely traditionally used and potent medicinal plant amongst all the thousands of medicinal plants. The pharmacological activities reported in the present review confirm that the 
therapeutic value of Berberis lycium is much more. The pharmacological activities of Berberis lycium proved that the plant has a leading capacity for the development of new good efficacy drugs in future. The present review gives detailed information about the potential use of Berberis lycium and Berberine in relation to its multiple therapeutic actions.

\section{Acknowledgement:-}

Author(s) would like to pass sincere thanks to faculty of Bhoj Mahavidhyalaya Bhopal, Barkatullah University Bhopal (M.P), India for humble support and providing necessary facilities and encouraging us throughout the work. We thank them for the freedom of thought, trust and expression which he bestowed upon us. We are greatly thankful to our friends for their valuable help.

\section{References:-}

1. Abidi P. Zhou Y. Jiang JD. and Liu J. (2005): Extracellular signal regulated kinase-dependent stabilization of hepatic low density lipoprotein receptor mRNA by herbal medicine berberine. Arterioscler Thromb Vasc. Biol., 25: 2170-6.

2. Ahmad, M., Alamgeer, and Sharif T. (2009): A potential adjunct to insulin Berberis lycium Diabet. Croatic 38(1): 1318.

3. Ahmad, M., Alamgeer., Chaudhary, MZ., Nadeem, M., Sharif T and Ahmad B. (2008): Hepatoprotective effect of Berberis lycium in hepatotoxic rabbits. Gomal. Uni. J. Res. 24:24.

4. Ahmed, E., Arshad, M., Ahmad, M., Saeed, M. and Ishaque M. (2004): Ethnopharmacological survey of some medicinal important plants of Galliyat areas of NWFP, Pakistan. Asian J. PI. Sci., 3(4): 410-415.

5. Ahmed, M., Alamgeer, Sharif, T., Zabta, CHM., and Akbar A. (2009): Effect of Berberis lycium on Lipid Profile in Alloxan Induced Diabetic Rabbits. Ethnobot. Leaflets 13. 702-708.

6. Ali, MN and Khan, AA. (1978): Pharmacognostic studies of Berberis lycium Royle and its importance as a source of raw material for the manufacture of Berberine in Pakistan, Pak. J. For., 26.

7. Anonymous. (1976): Wealth of India, Raw Materials, Publications and Information Directorate, SIR New Delhi, Vol. X. 36.

8. Anwar, AK., Ashfaq, M. and Nasveen, MA. (1979): Pharmacognostic studies of selected indigenous plants of Pakistan, (Peshawar, NWFP, and Pakistan: Pakistan Forest Institute).

9. Arayne, MS., Sultana, N. and Bahadur, SS. (2007): The Berberis story: Berberis vulgaris in therapeutics. Pak. J. Pharm. Sci., 20:83-92.

10. Asif, A., Kakub, G., Mehmood, S., Khunum, R., and Gulfraz, M. (2007): Wound Healing Activity of Root Extracts of Berberis lycium Royle in Rats. Phytother. Res. 21: 589-591.

11. Babbar, O. P., Chhatwal, V.K., and Ray, I.B. (1982): Effect of berberine chloride eye drops on clinically positive trachoma patients. Ind. J. Med. Res., 76:83-88.

12. Bae, E.A., Han, M.J. and Kim, N.J. (1998): Anti-helicobacter pylori activity of herbal Medicines. Biol. Pharmaceut. Bull., 21:990-992.

13. Baquar, SR. (1989): Medicinal and Poisonous plants of Pakistan, Karachi, Pakistan: Printas, 55.

14. Bruckner, C. (2000): Clarification of the Carpel number in Papaverales, Capparales and Berberidaceae. Botanical Review, 66(2): 155-307.

15. Cernakova, M. and Kostalova, D. (2002): Antimicrobial activity of berberine-a constituent of Mahonia aquifolium. Folia Microbiol (praha), 47: 375-8.

16. Chan, M.Y. (1977): The effect of berberine on bilirubin excretion in the rat. Comp. Med. East. West., 5:161-168.

17. Chand, N., Durrani, FR., Qureshi, MS. and Durrani, Z. (2007): Role of Berberis lycium in reducing serum cholesterol in broilers. Asian-Australasian. J. Ani. Sci. 20(4): 563-568.

18. Chandra, P. and Purhit, AN. (1980): Berberine contents and alkaloid profile Berberis species from different altitudes, Biochem, Sys, Eco., 8: 379-380.

19. Chevalier, A. (2001): Encyclopedia of medicinal plants, revised edition. Sydney (AUS): Dorling Kindersley.

20. Chiou, WF. Yen MH. And Chen, CF. (1991): Mechanism of vasodilatory effect of berberine in rat mesenteric artery. Eur. J. Pharmacol. 204: 35-40.

21. Choi, M. S., Oh, J. H., Kim, S. M., Jung, H. Y., Yoo, H. S., Lee, Y. M., Moon, D. C., Han, S. B., and Hong, J. T. (2009): Berberine inhibits p53-dependent cell growth through induction of apoptosis of prostate cancer cells. Int. J. Oncol., 34: 1221-1230.

22. Chopra, R.N., Nayar, S.L. and Chopra, I.C. (1996): Glossary of Indian Medicinal Plants". Council of Scientific and Industrial Research, New Delhi. 247.

23. Choudhary, VP., Sabir, M. and Bhide, VN. (1972): Berberine in Giardiasis. Indian Pediarr, 9: 143-6.

24. Chueh, W. H. and Lin, J. Y. (2011): Berberine, an isoquinoline alkaloid in herbal plants, protects pancreatic islets and serum lipids in nonobase diabetic mice. J. Agric. Food Chem., 59: 8021-8027 
25. Cui, G. L., Qin, X., Zhang, Y. B., Gong, Z. W., Ge, B. X. and Zang, Y. Q. (2009a): Berberine differentially modulates the activities of ERK, p38 MAPK, and JNK to suppress Th17 and Th1 T cell differentiation in type 1 diabetic mice. J. Biol. Chem., 284: 28420-28429.

26. Datta, SC., Nigam, M.C., Virmani, OP. and Siddiqui MS. (1976): Cold process for production of berberine hydrochloride from Berberis roots. Indian for, 139:204.

27. Gao, L., He, D., Liu, J. H., Yan, W., Gao, S. and Wang, L. (2011a): Berberine and itraconazole are not synergistic in vitro against Aspergillus fumigatus isolated from clinical patients. Molecules, 16: 9218-9233.

28. Gao, N., Zhao, T. Y. and Li, X. J. (2011b): The protective effect of berberine on beta-cell lipoapoptosis. J. Endocrinol. Invest., 34: 124-130.

29. Gentry, E.J., Jampani, H.B., and Keshavarz-Shokri, A. (1998): Anti-tubercular natural products: berberine from the roots of commercial Hydrastis canadensis powder. J. Nat. Prod., 61:1187-1193.

30. Ghosh, AK., Bhattacharyya, FK. and Ghosh, DK. (1985). Leishmania donovani: amastigote inhibition and mode of action of berberine. Exp. Parasitol, 60: 404-13.

31. Girish C, Koner BC, Jayanthi S, Rao KR, and Rajesh B. (2009). Hepatoprotective activity of six polyherbal formulations in paracetamol induced liver toxicity in mice Pradhan. Indian. J. Med. Res. 129:569.

32. Gosh AK., Bhattacharyya FK. and Ghosh, DK. (1990): Leishmaniadonovani: A mastigote Inhibition and mode of action of Berberine, Exp., Para., 60:404-413.

33. Gruenwald, J., Brendler, T. and Jaenicke, C. (2000): PDR for herbal medicines. Medical Economics Company, NJ. 313.

34. Gu, Y., Zhang, Y. F., Shi, X. Z., Li, X. Y., Hong, J., Chen, J., Gu, W. G., Lu, X., Xu, G. W. and Ning, G. (2010): Effect of traditional Chinese medicine berberine on type 2 diabetes based on comprehensive metabonomics. Talanta, 81: 766-772.

35. Gulfraz, M., Mehmood, S., Ahmad, A., Fatima, N., Praveen, Z. and Williamson, E. M. (2008): Comparison of the antidiabetic activity of Berberis lycium root extract and Berberine in Alloxan-induced Diabetic Rats. Phytotherapy Research, 22, 1208-1212.

36. Gulfraz, M, Qadir, G, Nosheen, F, and Parveen, Z. (2007): Antihyperglycemic effects of Berberis lycium Royle in alloxan induced diabetic rats, Diabet. Croatic. 36(3):49-54.

37. Gulfraz, M., Arshad, M., Nayyer, N., Kanwal, N., and Nisar, U. (2004): Investigation for bioactive compounds of Berberis lycium Royle and Justicia adhatoda L., Ethnobot, Leaflets, 1: 51-62.

38. Hamayun, M., Khan, A. and Khan, MA. (2005): Common medicinal folk Recipes of District Buner, NWFP, Pakistan, Ethnobot. Leaflets 1: 45, SIUC. USA.

39. Hasnain, N. (2014): Advances in Biomedicine and Pharmacy (An International J. of Biomedicine, Natural products and pharmacy), 1(1): 11-14.

40. Hostettmann, K., Marston, A. and Maillard, M. (1995): Phytochemistry of plants used in traditional medicine. Clarendon press, Oxford.

41. Hou, Q., Tang, X., Liu, H. Q., Tang, J. Q., Yang, Y., Jing, X. H., Xiao, Q., Wang, W., Gou, X. C. and Wang, Z. R. (2011): Berberine induces cell death in human Hepatoma cells in vitro by down regulating CD147. Cancer Sci., 102: $1287-1292$.

42. Huang, Cal. G., Zhong, C.L., Shan, W., Jiang, J. and Bing, J. (2002): Effect of berberine on arachidonic acid metabolism in rabbit platelets and endothelial cells. Thromb. Res., 106: 223-227.

43. Huang, Z., Wang, L., Meng, S., Wang, Y., Chen, T. and Wang, C. (2009): Berberine reduces both MMP-9 and EMMPRIN expression through prevention of p38 pathway activation in PMA-induced macrophages. Int. J. Cardiol., In Press.

44. Ikram, IM., Ensanul, Huq, M. and Warsi, SA. (1996): Alkaloids of Berberis lycium. Pakistan J. Sci. Ind. Res., 9:3436.

45. Imanshahidi, M. and Hosseinzadeh, H. (2008): Pharmacological and therapeutic effects of Berberis vulgaris and its active constituent, berberine. Phytother Res., 22: 999-1012.

46. Irshad, H. A., Pervaiz, H. A., Abrar, B. Y., Fahelboum, I., and Awen, B. Z. S. (2013): Antimicrobial activity of Berberis lycium Root extract. Trakia J. of Sciences, 11(1): 88-90.

47. Jeong, HW, Hsu, KC, and Lee, JW. (2009): Berberine suppresses pro-inflammatory responses through AMPK activation in macrophages. Am. J. Physiol. Endocrinol. Metabol. 296: 955-964.

48. Jussieu, A. L. de. (1789): Berberidaceae, nom. Cons. Genera Plantarum, 286.

49. Kaneda, Y., Tanaka, T. and Saw, T. (1990): Effects of berberine, a plant alkaloid, on the growth of anaerobic protozoa in axenic culture. Tokai J. Exp., Clin. Med., 15: 417-23.

50. Kaneda, Y., Torii, M. and Tanaka, T. (1991): In vitro effects of berberine sulfate on the growth of Entamoeba histolytica, Giardia lamblia and Tricomonas vaginalis. Ann. Trop. Med. Parasitol., 85:417-425.

51. Kang, D.G., Sohn, E.J., and Kwon, EK. (2002): Effect of berberine on Angiotensin converting enzyme and NO/cGMP system in vessels. Vacul Pharmacol, 39: 281-6.

52. Kaur, C. and Miani, SB. (2001): Fruits and vegetables healthy foods for new millennium, Indian Hort. 45(4): 29-32. 
53. Khan, M., Giessrgl, B., Vonach, C., Madlener, S., Prinz, S., Herbaceck, I., Hölzl, C., Bauer, S., Viola, K., Mikulits, W., Quereshi, RA., Knasmüller, S., Grusch, M., Kopp, B., and Krupitza, G. (2010): Berberine and a Berberis lycium extract inactivate Cdc25A and induce $\alpha$ tubulin acetylation that correlate with HL-60 cell cycle inhibition and apoptosis. Mut. Res. 683: 123-130.

54. Khan, MA., Jehanzeb, Shafiullah, Malik, SA., and Shafi, M. (2008): Hepatoprotective effects of Berberis lycium, Galium aparine and Pistacia integerrima in carbon tetrachloride (CCL4) treated rats. J. Post Grad. Med. Inst. 22(2): 91-94.

55. Kong, W.J., Zhang, H. and Song, DQ. (2009): Berberine reduces insulin resistance through protein kinase Cdependent up-regulation of insulin receptor expression. Metabolism. 58: 109-19.

56. Kulkarni, S.K. and Dhir, A. (2009): Current investigational drugs for major depression Exp. Opi. Invest. Drugs. 18:767-88.

57. Kulkarni, SK. and Dhir, A. (2007): Possible involvement of L-arginine-nitric oxide (NO)-cyclic guonosine monophosphate (cGMP) signaling pathway in the antidepressant activity of berberine chloride. Eur. J. Pharmacol, 569: 7783.

58. Kulkarni, SK. and Dhir, A. (2008): On the mechanism of antidepressant-like action of berberine chloride. Eur. J. Pharmacol, 589: 163-72.

59. Kuo, CL., Chi, CW. and Liu, TY. (2004): The anti-inflammatory potential of berberine in vitro and in vivo. Cancer Lett. 203: 127-37.

60. Lahiri, S.C. (1958): Positive and negative ionotropic effects of berberine on the cats' heart. Ann. Biochem. Exper. Med., 18:95.

61. Lamontagne, J., Pepin, E. and Peyot, M.L. (2009): Pioglitazone acutely reduces insulin secretion and causes metabolic deceleration of the pancreatic $\{$ beta $\}$-cell at Sub maximal glucose concentrations. Endocrinology, In Press.

62. Lau, C.W., Yao, X.Q., Chen, Z.Y., KO, W.H. and Haung, Y. (2001): Cardiovascular actions of berberine. Cardiovasc. Drug. Rev., 19:234-244.

63. Lau, CW., Yao, XQ. and Chen, ZY. (2001): Cardiovascular actions of berberine. Cardiovasc Drug Rev., 19: $234-44$.

64. Lee, S. Lim, HJ. and Park, HJ. (2007): Berberine-induced LDLR up-regulation involves JNK pathway. Biochem. Biophys Res. Commun, 362: 853-7.

65. Lee, Y.S., Kim, W.S. and Kim, K.H. (2006): Berberine, a natural plant product, activates AMP activated protein kinase with beneficial metabolic effects in diabetic and insulin-resistant states. Diabetes. 55:2256-2264.

66. Leet JE., Hussain SF., Minard, RD. and Sharma, M. (1982): Sindamine, Punjabine, and Gilgitine: Three new secobisbenzylisoquinolines alkaloids. Heterocycles. 19:2355-60.

67. Leet, JE., Slango, V., Hussain, SF., and Sharma, M. (1983): Chenabine and Jhelumine: Seco-bisbenzylisoquinolines or simple isoquinoline-benzylisoquinoline dimmers 7. Heterocycles, 20:425-9.

68. Letasiova, S., Jantova, S., Cipak, L. and Muckova, M. (2006): Berberine - anti-proliferative activity in vitro and induction of apoptosis/necrosis of the U937 and B16 cells. Cancer Lett., 239: 254-262.

69. LIU, Wei-hua., HEI, Zi-qing., NIE, Hong., TANG Fu-tian, HUANG He-qing, LI Xue-juan, DENG Yan-hui, CHEN Shao-rui, GUO Fen-fen, HUANG Wen-ge, CHEN Feng-ying and LIU, Peiqing. (2008): Berberine ameliorates renal injury in Streptozotocin-induced diabetic rats by suppression of both oxidative stress and Aldose reductase. Chinese. Med. J., 121:706-712.

70. Manske, RHF. (1998):The alkaloids: Chemistry and Pharmacology, (San Diego, California: Academic press, INC), 287.

71. Miana, GA. (1973): Tertiary dihydroprotoberberine alkaloids of Berberis lycium. Phytochemistry, 12: 1822-3.

72. Mohan, M., Pant, C.R. and Angra, S.K. (1982): Berberine in trachoma. Ind. J. Opthalmol. 30:69-75.

73. Nadkarni, KM. (1980): Indian Material Medica, (Bombay, India: Popular Parakashan Depot), 180-190.

74. Nakamoto, K., Tamamoto, M., Hamada, T. (1995): In vitro study on the effects of trial denture cleansers with berberine hydrochloride. J. Prosthet. Dent., 73:530-533.

75. Nandkarni, A.K. (1976): Nadkarni's Indian Materia Medica Popular Prakashan, Pvt. Ltd. Bombay.

76. Nidaullah, H., Durrani, FR., Ahmad, S., Jan, IU, and Gul, S. (2010): Aqueous extract from different medicinal plants as anticoccidial, growth promotive and immunostimulant in broilers. ARPN. J. Agric. Biol. Sci. 5(1):53-59.

77. Olmez, E. and Ilhan, M. (1992): Evaluation of alpha-adreno receptor antagonistic action of berberine in isolated organs. Arzneimittelforschung, 42: 1095-97.

78. Parwardhan, B. and Hopper, ML. (1992): Ayurveda and future drug development. J Altern Complement Med. 3: 911.

79. Sack, RB. and Froehlich, JL. (1982): Berberine inhibits intestinal secretary response of Vibrio cholera and Escherichia coli enterotoxins. Infect Immun., 35:471-5.

80. Sack, RB. and Froehlich, JL. (2000): Berberine- one herb in many ways. Altern Med. Rev., 5: 175-7.

81. Saha, P., Bhattacharjee, S., Sarkar, A., Manna, A., Majumder, S. and Chatterjee, M. (2011): Berberine chloride mediates its anti-leishmanial activity via differential regulation of the mutagen activated protein kinase pathway in macrophages. Plos One, 6. 
82. Saha, P., Sen, R., Hariharan, C., Kumar, D., Das, P. and Chatterjee, M. (2009): Berberine chloride causes a caspaseindependent, apoptotic-like death in Leishmania donovani promastigote. Free Radic. Res., 43: 1101-1110.

83. Serry, T. M. and Bieter, R.N. (1940): A contribution of pharmacology of berberine. Pharmacol. Expr. Ther. 69:64-67.

84. Shah, H., Shad, A. A., Perveen, S., Khattak, S. and Khattak, K. F. (2003): Physicochemical composition of wild medicinal plant Berberis lycium, J. Applied Sci., 3: 370-375.

85. Sharma, R. Dr. (2003): Medicinal Plants of India; an Encyclopaedia, 33.

86. Singh, M., Srivastava, S., and Rawat, AKS. (2007): Antimicrobial activities of Indian Berberis species. Fitoterap. 78: 574-576.

87. Singh, M., Srivastava, S., and Rawat, AKS. (2009): Antimicrobial Studies of Stem of Different Berberis Species. Nat. Prod. Sci. 15(2): 60-65.

88. Srivastava, S., Vartica, R., Srivastava, M., Rawat, AKS. and Shanta, M. (2006): Estimation of heavy metals in different Berberis species and its market samples, Env., Monit, Assess., 116: 315-320.

89. Sun, D. Abraham,s SN. and Beachey EH. (1988): Influence of berberine sulfate on synthesis and expression of Pap fimbrial adhesion in uropathogenic E. coli. Antimicrob agents. Chemother., 32: 1274-77.

90. Sun, D., Courtney, H.S. and Beachey, E.H. (1988): Berberine sulfate blocks adherence of Streptococcus pyrogenes to epithelial cells, tibronectin, and hexadecane. Antimicrob. Agents. Chemother., 32:1370-1374.

91. Sun, X., Zhang, X. and Hu, H. (2009a): Berberine inhibits hepatic stellate cell proliferation and prevents experimental liver fibrosis. Biol., Pharm., Bull., 32:1533-1537.

92. Sun, X., Zhang, X. D., Hu, H., Lu, Y. N., Chen, J., Yasuda, K. and Wang, H. Y. (2009b): Berberine Inhibits Hepatic Stellate Cell Proliferation and Prevents Experimental Liver Fibrosis. Biol. Pharm. Bull., 32: 1533-1537.

93. Szeto, S. Yow CMN. and Fung KW. (2002): Characterization of berberine on human cancer cells in culture. Turk J. Med. Sci., 32: 363-8.

94. Tewary, DK., Bhardwaj, A., and Shanker, A. (2005): Pesticidal activities in five medicinal plants collected from mid hills of western Himalayas. Indus. Crop. Prod. 22: 241-247.

95. Turner, N., Li, J.Y. and Gosby, A. (2008): Berberine and its more biologically available derivative, dihydroberberine, inhibit mitochondrial respiratory complex I: a mechanism for the action of berberine to activate AMP-activated protein kinase and improve insulin function. Diabetes., 57:1414-1418.

96. Usmanghani, K., Saeed, A. and Alam, MT. (1997): Indusyunic medicine, (Karachi, Pakistan: University of Karachi press), 120.

97. Watt, G. (1972): Dictionary of Economic Products of India, Reprinted edition periodical expert. Delhi, Vol. VI (Pt. IV), 83.

98. WHO, (1977): Resolution-Promotion and development of Training and Research in Traditional Medicine, WHO document, 30-49.

99. Wong, KK. (1998): Mechanism of the aortic relaxation induced by low concentrations of berberine. Planta. Med. 64: 756-7.

100.Xingshen, Ye., Yibin, F., Yao, T., Kwan-Ming Ng., Saiwah, T., George, K. K., Chowing S., Yanbo Z., Jun T., Jiangang S. and Seiichi K. (2009): Hepatoprotective effects of Coptidis rhizome aqueous extract on carbon tetrachloride-induced acute liver hepatotoxicity in rats. J. Ethno, Pharmacol, 124:130-136.

101. Yin, J., Xing, H., Ye J. (2008): Efficacy of berberine in patients with type 2 diabetes mellitus. Alt. Med. Rev., 57:712717.

102. Yuan, J., Shen, XZ. and Zhu, XS. (1994): Effect of berberine on transit time of human small intestine. Zhongguo Zhong Xi. Yi Jie He Za Zhi. 14:718-20.

103.Zaman, MB. and Khan (1970): Hundred drug plants of West Pakistan. (Peshawar, NWFP: Pakistan Forest Institute.

104.Zhang, B. J., Xu, D., Guo, Y., Ping, J., Chen, L. B. and Wang, H. (2008a): Protection by and antioxidant mechanism of berberine against rat liver fibrosis induced by multiple hepatotoxic factors. Clin. Exp. Pharmacol. Physiol., 35: 303-309.

105.Zhang, Y., Li, X., Zou, D., Liu W., Yang, J., Zhu, N., Huo, L., Wang, M., Hong, J., Wu, P., Ren, G. and Ning, G. (2008c): Treatment of type 2 diabetes and dyslipidemia with the natural plant alkaloid berberine. J. Clin. Endoc. Metab., 93: 2559-2565

106.Zhou, J. Y., Zhou, S. W., Tang, J. L., Zhang, K. B., Guang, L. X., Huang, Y. P., Xu, Y., Ying, Y., Zhang, L. and Li, D. D. (2009a): Protective effect of berberine on beta cells in Streptozotocin- and high-carbohydrate/high-fat dietinduced diabetic rats. Europ. J. Pharmacol., 606: 262-268

107.Zhou, J. Zhou, S. and Tang, J. (2009b): Protective effect of berberine on bête cells in Streptozotocin and highcarbohydrate/high-fat diet-induced diabetic rats. Eur. J. Pharmacol., 606: 262-8.s. 